\title{
ViOlÊNCIA E REFINAMENTO DISCURSIVO EM A Grande Arte, de Rubem FonseCa
}

\author{
VIOLENCE AND REFINED DISCOURSE IN
} A Grande ARte, by Rubem FonseCA

\section{Murilo Eduardo dos Reis Maria Célia de Moraes Leonel}

Universidade Estadual Paulista Júlio de Mesquita Filho Araraquara - SP, Brasil

\section{Resumo}

Rubem Fonseca é reconhecido, desde o lançamento de sua primeira publicação, pela representação da violência associada ao uso de uma linguagem sofisticada. Tal característica leva Alfredo Bosi a inseri-lo na corrente literária "brutalista”. Este artigo pretende verificar como é representada a brutalidade derivada dos desníveis sociais na sociedade brasileira em $A$ grande arte, de 1983, segundo romance policial do autor. $\mathrm{O}$ escritor utiliza-se de aprimoradas técnicas narrativas para representar de maneira detalhada situaçóes de violência explícita que envolvem o protagonista-narrador e outras personagens como o matador de aluguel. Com apoio em estudos sobre o romance policial, a narrativa brasileira e alguns problemas de técnica da narrativa, expomos a imbricação entre representação da violência, a crítica à desigualdade social e a composiçáo própria do romance policial, construídas por um discurso requintado.

Palavras-chave: Rubem Fonseca, romance policial, violência.

\section{Abstract}

Since the release of his first publication, Rubem Foseca has been associated to a representation of violence through sophisticated language. Such characteristic led Alfredo Bosi to include Fonseca in the "brutalist" literary movement. This article intends to examine how brutality resulting from social differences in Brazilian society is represented in $A$ grande arte (1983), the second crime novel written by Fonseca. In this novel, the author uses refined narrative techniques to represent in detail situations of explicit violence that involve the protagonist-narrator and other characters and whose main agent

\section{Resumen}

Rubem Fonseca es reconocido, desde el lanzamiento de su primera publicación, por la representación de la violencia asociada al uso de un lenguaje sofisticado. Tales características llevarían a Alfredo Bosi a insertarlo en la corriente literaria "brutalista". Este trabajo pretende verificar cómo es representada la brutalidad resultante de los desniveles sociales en la sociedad brasileña en $A$ grande arte, de 1983, la segunda novela policial del autor. El escritor se vale de cuidadosos procedimientos narrativos para representar de manera detallada situaciones de violencia que envuelven al 
for violence is a contract killer. Based on studies about crime novels, Brazilian narrative and narrative techniques, we will reveal the link between the representation of brutality, criticism of social inequality and composition of crime novels achieved through sophisticated writing.

Keywords: Rubem Fonseca, crime novel, violence. protagonista narrador y a otros personajes, como el sicario. Partiendo de los estudios sobre la novela policial, la narrativa brasileńa y algunos problemas de técnica narrativa, apuntamos para la imbricación entre la representación de la violencia, la crítica a la desigualdad social y la composición propia del género policial, construidas a través de un requintado discurso.

Palabras claves: Rubem Fonseca, novela policial, violencia.

A matéria-prima principal da nada otimista literatura policial de Rubem Fonseca deriva dos desníveis sociais do país por ele representados em becos suburbanos e em luxuosos apartamentos de políticos e empresários. Nessas condiçôes da sociedade, surgem assassinos cruéis que transitam das camadas mais altas às mais baixas.

Abordamos aqui a imbricação entre técnicas narrativas apuradas e a crueldade de matador de aluguel resultante da desigualdade social no romance A grande arte de 1983. O boliviano Camilo Fuentes, colocado a uma distância considerável dos confortos do capitalismo, encontra na profissão de homicida contratado uma forma de sobreviver numa urbe em que é invisível. Verificamos os motivos que o levaram a se aperfeiçoar na arte de matar e a sentir prazer quando o alvo é determinado tipo social, como também o improvável olhar crítico do qual é possuidor.

Antes de chegarmos aos vetores dessa brutalidade, faz-se necessária uma breve incursão pela história e pelo modo como é narrada.

\section{O advogado-detetive narrador da história}

A grande arte (1990), segundo romance publicado pelo autor, traz a investigação de assassinatos em série de três mulheres que conduz o advogado Paulo Mandrake ao submundo do crime na fronteira do Brasil com a Bolívia. Assassinos profissionais, com conhecimento quase acadêmico no manejo de facas, fazem parte de um elenco que inclui prostitutas, policiais e advogados, anti-heróis sobreviventes em um mundo violento e implacável.

$\mathrm{O}$ relato inicia-se como na maioria dos romances policiais. Um assassino misterioso faz a primeira vítima: mata uma prostituta por esganadura e, como única pista, deixa marcada à faca no seu rosto a letra $\mathrm{P}$, estabelecendo-a como o enigma a ser decifrado: "Não haveria impressóes digitais, testemunhas, indícios que o identificassem. Apenas sua caligrafia." (FONSECA, 1990, 
p. 10). Essa marca particular do criminoso dificilmente levará a ele pelos métodos científicos de investigação utilizados pela polícia - ou até mesmo, se fosse o caso, por Sherlock Holmes.

Em seguida ao relato do assassinato, revela-se que a instância narrativa dos acontecimentos é Mandrake. Personagem emblemática na obra do escritor, o mulherengo advogado já havia protagonizado os contos "O caso de F. A." de 1967, "Dia dos namorados" de 1975 e "Mandrake" de 1978. Depois de $A$ grande arte de 1983, ele reaparece nos romances $E$ do meio do mundo prostituto só amores guardei ao meu charuto de 1997, e Mandrake, a Bíblia e a bengala, publicado em 2005. Recentemente, no ano de 2017, o escritor promoveu mais um retorno da icônica personagem no conto "Calibre 22", pertencente à coletânea homônima.

No romance em pauta, ele vivenciou boa parte dos fatos e tem, em seu poder, os cadernos do poderoso executivo Thales de Lima Prado, documento que lhe fornece informaçóes sobre acontecimentos relativos aos crimes dos quais não participou. Contrariando a característica do narrador memorialista presente nos romances de enigma, Rubem Fonseca traz o advogado, que exerce a função de detetive, como o narrador do romance. Assim, ele está posicionado temporalmente à frente da história - mas sem nenhuma demarcação cronológica precisa:

Os acontecimentos foram sabidos e compreendidos mediante minha observação pessoal, direta, ou seguindo o testemunho de alguns dos envolvidos. Às vezes interpretei episódios e comportamentos - não fosse eu um advogado acostumado, profissionalmente, ao exercício da hermenêutica. (FONSECA, 1990, p. 10).

Essa narração em primeira pessoa é o que Antonio Candido (2011, p. 254-255) classifica como ultrarrealismo sem preconceitos, um "realismo feroz" por meio do qual Rubem Fonseca agride o leitor pela violência temática veiculada por uma técnica narrativa: funde o ser e o agir em uma fala marginal, "[...] propondo soluções alternativas na sequência da narração, avançando as fronteiras da literatura no rumo duma espécie de notícia nua e crua da vida." (CANDIDO, 2011, p. 255).

Mandrake toma conhecimento do assassinato da garota de programa quando um sujeito chamado Roberto Miltry o procura para contratar seus serviços. Miltry deseja que ele o ajude a recuperar uma fita VHS com imagens comprometedoras que estaria no apartamento de uma massagista - que, assim como a prostituta, também será assassinada.

Ao investigar o paradeiro dessa fita, o advogado atrai a atençáo de criminosos. Como resultado, Mandrake e Ada - sua namorada - sofrem um atentado em que ele é esfaqueado e ela, estuprada. Posteriormente, ele 
descobre que um dos homens que invadiram seu apartamento é Camilo Fuentes. A descoberta dá-se pelo que Aristóteles (2005, p. 36) classifica como "reconhecimento". No ataque dos criminosos, um colar com pingente em forma de unicórnio é roubado. Fuentes é detido em uma batida da polícia, suspeito de tráfico de drogas. Raul, policial amigo de Mandrake, chama-o para comprovar se o homem seria um dos criminosos. Através de um espelho utilizado para a delação de culpados e a proteção de testemunhas, o advogado vê o seu colar pendurado no pescoço de Camilo. Ciente de que foi ele quem cometeu as atrocidades, começa a segui-lo, em uma jornada do interior de São Paulo à fronteira mato-grossense com a Bolívia, no trem da ferrovia Bauru-Corumbá.

\section{O boliviano matador de brasileiros}

A partir do relato de Mandrake, que sai no encalço de Camilo Fuentes nos vagóes que seguem até a fronteira boliviana, o leitor depara-se com um narrador demiurgo. Assim, tem-se o retrato das demais personagens por meio de uma instância narrativa que conhece seus sentimentos mais cruéis.

Porém, ocorre uma mudança de ponto de vista surpreendente, para um romance policial, no capítulo dez, quando o advogado-detetive passa a narrar os acontecimentos pelo olhar de Camilo Fuentes, no momento em que ele mantém relaçôes sexuais com Zélia, mulher que conhece no vagãorestaurante. Trata-se da primeira oportunidade em que se insere na narrativa uma segunda perspectiva:

Camilo Fuentes acreditava firmemente que, para sobreviver no mundo hostil em que vivia, era preciso estar preparado para matar. Seu pai fora morto na fronteira porque vacilara ao enfrentar seu assassino. Camilo tinha sete anos quando isso aconteceu, mas seu tio Miguel lhe contara tudo: o homem que matara seu pai era brasileiro, como eram brasileiros os usurpadores de larga parte do território boliviano, um território tão grande que se transformara num dos estados da República do Brasil, o vizinho imperialista que, com a conivência dos governantes bolivianos corruptos, há séculos roubava as riquezas naturais de seu país. Camilo, na infância e na adolescência, sofrera a arrogância de seus vizinhos ricos do outro lado da fronteira, aos quais prestava pequenos serviços humilhantes em troca de pagamento miserável. Por esse motivo e outros mais obscuros, odiava os brasileiros.

Zélia é muito estúpida para ser perigosa, pensou Camilo enquanto mandava que ela ficasse de quatro no chão da cabine. Em seguida começou a possuí-la como se faz com uma cadela, chamando-a de puta brasileira, espancando-a e fazendo-a gemer e pedir mais, em gritos abafados pelo barulho das rodas do trem.

[...] Havia no trem outra pessoa suspeita, um sujeito de barba que o observava 
dissimuladamente no carro-restaurante e desviara os olhos como um maricón indeciso, procurando contacto; mas aquele sujeito de olhar hostil e dentes sempre trincados não era um homossexual. Precisava também ser vigiado. (Felizmente Fuentes náo me reconhecera.). (FONSECA, 1990, p. 104).

O final mostra a nítida consciência do assassino com relação ao que o rodeia. Portanto, numa parte consideravelmente longa, o narrador onisciente adentra a mente de Camilo Fuentes. No recorte acima, além da mudança no ponto de origem da perspectiva, o narrador, ao relatar fatos dos quais não participou, deixa de ser autodiegético para se tornar heterodiegético, de acordo com a terminologia genettiana.

Segundo Paul Ricoeur (2010, p. 162), o ponto de vista define, em uma narrativa em terceira ou primeira pessoa, em que direção aponta o olhar do narrador às personagens e das personagens umas às outras. De acordo com o autor, a adoção de variados pontos de vista dá ao escritor a oportunidade de multiplicar e incorporar diferentes ângulos de visão na composição da obra.

É exatamente o procedimento adotado pelo sofisticado narrador de Rubem Fonseca que, em outra passagem do livro, posiciona a lente de sua câmera noutra personagem e, a partir daí, é o olhar de Zélia que se manifesta. Novamente, o narrador heterodiegético alia-se à focalização onisciente, movimentando o anel de focalização para que a imagem se turve com a intenção de representar a visão que a personagem tem de Camilo Fuentes enquanto fazem sexo:

Os movimentos rigorosos de Fuentes faziam o suor pingar da sua cabeça sobre a face e os olhos de Zélia, cobrindo sua visão com uma lente líquida ardente que tornava disforme a figura do homem curvado sobre ela. (FONSECA, 1990, p. 105).

A mudança de focalização, paradoxalmente - pois há a intervenção da subjetividade da personagem não narradora - contribui ainda para a objetividade (e crueldade) do narrador do romance policial à qual se referem Boileau e Narcejac (1991, p. 61) e que é visível nas páginas de Rubem Fonseca. A sordidez realista frisada pelos autores franceses foi detectada por Antonio Candido (2011, p. 254-255) na obra do escritor brasileiro, conforme mencionamos, como um "ultrarrealismo feroz". Não há descrição de sofrimento por parte da vítima. Tudo acontece naturalmente, com a mesma imparcialidade de uma notícia de jornal.

Também, nesse aspecto, o romance de Rubem Fonseca encaixa-se no tipo literário do romance policial americano que - de acordo com Boileau e Narcejac (1991, p. 59), ao contrário de "narrativas de espanto" classificadas como thrillers - não tem como objetivo causar medo, mas fazer mal ao leitor 
pela crueza das cenas. Um dos momentos em que isso ocorre é a passagem na qual se relata que, após descobrir que Mercedes - amiga de Zélia e eventual amante de Mandrake - é uma agente disfarçada da polícia federal que estava em seu encalço, Camilo Fuentes tira a sua vida com frieza e requintes de crueldade:

Mercedes correu para a porta, mas Fuentes atingiu-a com violento golpe no rosto fazendo-a cair no chão. Em seguida sentou-se sobre a barriga de Mercedes, com os joelhos abertos apoiados no chão, e esbofeteou-a com força, seguidamente. Mercedes sabia que era impossível sair daquela posição; num gesto rápido estendeu os dois braços tentando perfurar com as unhas os olhos de Fuentes. Com os dedos da mão direita conseguiu atingir o globo ocular esquerdo do homem, mas a unhas da mão esquerda atingiram apenas o supercílio. Ao notar que fora ferido, Fuentes deixou de lado a pequena brincadeira que pretendia manter com a mulher antes de matá-la. Pegou o braço direito de Mercedes e partiu-o em dois pedaços e passou a golpear com os punhos e os cotovelos o rosto desprotegido de Mercedes até transformálo numa polpa de carne sangrenta. Para certificar-se de que a vaca brasileira estava morta, Fuentes torceu sua cabeça lentamente até sentir seu pescoço estalar. Depois, praguejando, foi até o banheiro lavar-se. No olho esquerdo havia um pedaço de unha que Fuentes retirou com a máo trêmula. Estava cego daquele olho. Furioso, voltou para o quarto e chutou o corpo caído de Mercedes. (FONSECA, 1990, p. 125).

Vemos nessa passagem elementos narrativos que dão noção da implacável impiedade de Camilo Fuentes. A descrição detalhada e objetiva dos movimentos (golpes no rosto, bofetadas seguidas, braço partido em dois, cabeça sendo torcida até o limite suportável pelos ossos do pescoço, globo ocular perfurado, rosto que se transforma em uma disforme massa de carne) aproxima o leitor da ideia do que é matar alguém friamente. No trecho em que o narrador se fixa nas açóes exteriores do assassinato, a onisciência narrativa penetra o seu interior - "deixou de lado a pequena brincadeira" (nota-se a atrocidade do trecho em itálico).

Mas a onisciência não se resume apenas ao algoz, também é levada à presa que tenta escapar do predador. Para indicar isso, o narrador relata a consciência de Mercedes de que, na posição em que se encontrava, seria praticamente impossível safar-se do terrível fim que a aguardava. A única maneira que encontra para ter algum tipo de sobrevida é, num último e desesperado gesto, perfurar o olho de Fuentes com as unhas. Isso apenas serve para deixá-lo ainda mais ensandecido, o que é comprovado pelo discurso indireto livre que apresenta seu julgamento de valor com relação à policial: uma "vaca brasileira". O discurso indireto livre reaparece no final do trecho analisado a seguir. 
Quando Camilo Fuentes perde a vista esquerda, Rubem Fonseca lança máo de um recurso oportuno para que o leitor saiba da grande dificuldade que passaria a acompanhá-lo e como seria enxergar apenas com um dos olhos. Heterodiegeticamente o narrador relata uma cena em que Fuentes testa a possibilidade de captar a imagem para a qual o olhar é direcionado, momento em que percebe que enxerga apenas parcialmente:

$\mathrm{Na}$ rua, Fuentes ficou olhando os olhos das pessoas que passavam por ele. Nunca estivera tão indeciso em sua vida. Com o olho direito, que sempre fora melhor do que o esquerdo, que sofria de uma pequena miopia, estava enxergando melhor do que nunca. Havia um lado que ele náo podia ver sem virar a cabeça. Levantou a mão esquerda e a colocou ao lado da cabeça, uma continência com a mão errada: mas ele não via a mão, só via o perfil do seu próprio nariz. Isso era perigoso. (FONSECA, 1990, p. 139).

A frase final tanto pode ser da lavra da personagem - e, nesse caso, teríamos discurso indireto livre - como do narrador, o que, além da ambiguidade, pode trazer a passagem da visão do exterior da personagem para o seu interior.

Voltando à questão da exposição da crueza, Hal Foster (2017, p. 130 131) reflete sobre a obra Desastre de ambulância de Andy Warhol de 1963, na qual a figura do corpo de uma mulher pendurado em uma ambulância acidentada intenciona chocar o espectador. Porém, segundo Foster (2017, p. 131), a primeira sensação traumática é encoberta pela repetição da imagem - o que também poderia gerar um segundo tipo de trauma -, procedimento que aproxima aquele que a observa do real. De acordo com o crítico, as reproduçóes que se fixam no real traumático contribuem não apenas para o efeito de absurdo de imagens afetivas e sem afeto, mas também para a existência de observadores impassíveis como o narrador de Rubem Fonseca, que narra as atrocidades sofridas por Mercedes com a objetividade característica de uma notícia de jornal.

Seguindo a linha de pensamento de Foster, a repetição de situaçóes de violência explícita, como a do assassinato de Mercedes, faz com que o leitor tenha o choque inicial encoberto por novos incômodos. Tal situação pode acabar automatizando os fatos do relato, porém, mais do que as cenas de brutalidade visceral, o que pode realmente causar espanto é a atitude do observador indiferente à selvageria - posição, em A grande arte (1990), ocupada por Mandrake, o apático narrador da história e manipulador do discurso.

Atualmente, pode-se dizer que, no fotojornalismo, há um retorno da crueza característica do romance policial fonsequiano e da imagem explorada por Warhol. Em 2017, o World Press Photo elegeu a imagem captada pelo turco Burhan Özbilici como a melhor do ano. Nela, o também turco Mevlüt Mert 
Altintas, de terno e gravata, aponta a máo esquerda para o alto, empunhando uma pistola na direita e vociferando ao lado de um cadáver no chão. $\mathrm{O}$ corpo sem vida é do embaixador russo na Turquia, Andrei Karlov, que acabara de ser assassinado pelo atirador numa galeria de arte.

Esse tipo de imagem que transborda realismo é frequentemente comparado a um frame de cinema. O figurino do assassino, nesse caso, assemelha-se ao das personagens do filme Cáes de aluguel de 1992, dirigido por Quentin Tarantino. Pode-se dizer que é a mesma selvageria narrada por Mandrake, que relata detalhadamente os movimentos furiosos de Camilo Fuentes que levam Mercedes à morte em poucos minutos. É, também, a violência inesperada captada por Warhol em seu painel.

Os três casos, o literário, o fotográfico e o cinematográfico, mostram de maneira objetiva (característica das câmeras fotográficas e da linguagem jornalística) como o sofrimento do outro pode ser automatizado aos olhos do espectador e ser transformado em obra de arte.

\section{A violência como método de sobrevivência}

De acordo com Vera Lúcia Follain de Figueiredo (2003, p. 19), a violência representada por Rubem Fonseca de diferentes ângulos seria uma sina que se distribui em diferentes dimensóes do comportamento humano e seria justificada como um método de sobrevivência do indivíduo.

O comportamento do boliviano Camilo Fuentes pode ser explicado por esse viés. O preconceito dos vizinhos brasileiros, que o coloca à margem devido à sua origem e aparência indígena, faz com que ele sempre esteja com a guarda levantada quando se depara com alguém nascido no país vizinho. Desde muito cedo, Fuentes aprendeu que os brasileiros hostilizam estrangeiros, como na oportunidade em que, ainda adolescente, em um bar, viu-se na obrigaçáo de confrontar dois homens que zombaram do estado de suas roupas:

Os homens riram dele, "O defunto é menor?", e um tentou jogá-lo ao chão, botando o pé na frente para que Fuentes tropeçasse ao passar. Porque ele era um índio boliviano; porque ele era pobre e estava mal vestido; porque os brasileiros eram uns cães nojentos. Fuentes parou ao lado da mesa olhando os homens. [...] Os homens olharam Fuentes de volta, arrogantes, zombeteiros. Num gesto rápido Fuentes estendeu a mão, agarrou um dos homens pelos cabelos, puxou sua cabeça para a frente e desferiu-lhe um forte murro em cima do nariz. Ouviu-se o barulho de ossos partindo antes de o homem cair, arrastando na queda sua cadeira. $\mathrm{O}$ outro homem, surpreendido com a rapidez de Fuentes, levantou-se, de punhos cerrados à frente, em atitude de boxeur, com a guarda alta. Bastou apenas um soco no estômago para jogá-lo ao chão sem sentidos. (FONSECA, 1990, p. 133-134). 
Longe das benesses oferecidas por trabalhos legais, Fuentes encontra, na função de matador de aluguel, um meio de obter recursos financeiros, ofício que ele executa com maestria. Depois de matar Mercedes, o boliviano passa a ser perseguido pela polícia. Temendo que ele seja capturado e confesse o esquema no qual estava envolvido, seus empregadores também saem em seu encalço com o intuito de eliminá-lo, mas ele dá conta de todos os lacaios que surgem em seu caminho. Por conta disso, os antigos patróes contratam Hermes, especialista em facas que também orientou Mandrake nesse mister, para matar o boliviano.

Quando os dois assassinos se encontram, dá-se a representação de uma cena em que estáo presentes dois tipos de habilidade: a dos combatentes e a do narrador onisciente. Mandrake adota o ponto de vista de Hermes que, ao contrário de Fuentes, possui grande conhecimento das variaçóes de golpes com armas brancas. Porém, apesar de não ser versado na arte do Percor ${ }^{1}$, seu adversário possui o que Hermes qualifica como ódio frio e calculado. Ao invés de mover-se bruscamente e abrir a guarda, o boliviano, empunhando um machete, mantém-se inerte.

O modo como os adversários se portam, cada qual estudando o movimento do outro e analisando as possibilidades de aplicarem um golpe fatal, é semelhante aos duelos representados em filmes de samurai, como Rashomon de Akira Kurosawa ou Kill Bill de Quentin Tarantino. Nesses longas-metragens, há cenas que também exibem combates inicialmente muito estudados e que são resolvidos com um único e cirúrgico ataque. $\mathrm{O}$ romance de Rubem Fonseca apresenta a vitória da força bruta de Fuentes sobre a habilidade enciclopédica de Hermes:

O sabre grosso e afiado desceu com uma velocidade incrível. O desvio de Hermes foi rápido e ele conseguiu livrar a cabeça. Náo impediu, porém, que o machete atingisse em cheio seu ombro, dilacerando os músculos trapézio e pequeno romboide e fraturando os ossos da clavícula e da omoplata. A faca continuou firme na mão de Hermes, mas ele caiu sentado no chão, o rosto impassível, lívido. O enchimento do paletó diminuíra um pouco a força do golpe, impedindo que o aço entrasse mais fundo. Hermes sentiu o silêncio ficar mais abafado, como se tivessem colocado algodáo nos seus ouvidos. Mas mesmo assim conseguiu ouvir o sibilar da lâmina cortando o ar antes de chocar-se com a sua têmpora. (FONSECA, 1990, p. 291-292).

Mais uma vez a onisciência do advogado-narrador que se póe a contar a história nos aproxima da sensação de Hermes ao relatar a espécie de surdez que o acometeu ao sentir o ombro dilacerado pela afiada lâmina do machete.

1 "[...] sigla que definia um conjunto de técnicas e táticas de manejo de armas brancas." (FONSECA, 1990, p. 81). 
Ela aumenta o efeito de realidade para o leitor na mesma proporçáo que o zoom de uma câmera promove. Esse detalhamento é encerrado pelo último som ouvido pelo assassino de aluguel: o ruído sibilante do metal cortando o ar até partir seu crânio, escurecendo o resto de sua consciência.

\section{O assassino como crítico da estrutura social}

Conforme Sandra Lúcia Reimão (2005, p. 12), os detetives noir ${ }^{2}$ apresentam-se como críticos da estrutura social em que vivem e investem contra essa situação por meio da rudeza, do sarcasmo, da insolência e da violência. Essa mesma característica também se faz presente no olhar de Camilo Fuentes, quando o narrador introduz a interioridade do assassino ou permite que parta dele a visão dos fatos, apontando para a absurda condição em que vivem os habitantes da periferia.

O boliviano apresenta traços do bandido revoltado com os desníveis sociais, mas também do cruel criminoso que parte o braço da vítima antes de matá-la com golpes no rosto. Apesar de ser um assassino frio e impiedoso, Fuentes é possuidor do olhar crítico que julga, a todo o momento, as mazelas causadas pela desigualdade social. $\mathrm{Na}$ ficção em geral, os criminosos não consideram a situação social à sua volta. Matam pelo dinheiro, não importando a classe de seu alvo. Assim, o assassino boliviano é apresentado como uma exceção: um matador de aluguel com princípios sociais.

Um exemplo dessa situação é quando, depois de matar um advogado (com uma corda de náilon disfarçada de iô-iô) sob encomenda, Fuentes exerce a sua secreta vingança contra um "país de mendigos e ladróes ricos" (FONSECA, 1990, p. 135). Ele é o bandido nobre que Ernest Mandel (1988, p. 26) afirma ter se transformado no cruel criminoso - o olhar provido de crítica social não o impede de acabar com a vida de quem estiver no seu caminho:

Revistou as roupas de Barreto tirando a carteira, o relógio e a aliança. [...] Pouco adiante Fuentes jogou a carteira e os documentos numa cesta de lixo; a aliança e o relógio enfiou num bueiro, e o dinheiro, oito notas de mil, deu para vários mendigos que encontrou na rua. (FONSECA, 1990, p. 135).

O que move Fuentes não é um ódio cego por tudo e por todos. Seus movimentos são calculados. Ele só faz o que foi pago para fazer e sua tarefa torna-se ainda mais prazerosa quando tem a oportunidade de matar empresários milionários, os quais, na sua visão, são aproveitadores e exploradores dos mais pobres.

\footnotetext{
${ }^{2}$ De acordo com Ernest Mandel (1988, p. 63), trata-se da tradução de "romance negro" para o francês; costuma ser vinculada à literatura do pós-guerra das décadas de 1940 e 1950, iniciada por Marcel Duhamel, idealizador da série de romances policiais intitulada Série noire.
} 
Para Tânia Pellegrini (1999, p. 104), A grande arte subverte o rótulo do romance policial ao apresentar um trabalho linguístico que se distancia da linguagem recorrente dessa modalidade e apontar a complexidade e as motivaçóes humanas, colocando-as como consequência do contexto econômico e social do Brasil contemporâneo (como os motivos que levam Camilo Fuentes a se tornar um impiedoso assassino). Por essas razōes, a narrativa de Rubem Fonseca diferencia-se do caráter reconfortante peculiar a esse tipo de romance no qual o detetive sempre triunfa e o criminoso nunca escapa impune. Náo há nele qualquer intenção de entreter o leitor e aliviar o tédio do cotidiano, mas, sim, de alertá-lo sobre as podridóes presentes em terras brasileiras.

De acordo com a autora (PELLEGRINI, 1999, p. 93), apesar das semelhanças com escritores de romance policial, Rubem Fonseca é muito mais sofisticado do que seus precursores no tratamento das razóes do crime, a ponto de ser possível questionar a classificação de policial atribuída a boa parte de suas narrativas. No caso de $A$ grande arte, considerando o complexo trabalho de estruturaçáo do texto de Mandrake, juntamente com o final sem solução definitiva, pode-se afirmar que o livro não é um romance policial, suposição motivada pelo fato de lógica e razão (elementos básicos dos contos de Edgar Allan Poe) serem questionadas.

Nosso exame da produção fonsequiana, especialmente de $A$ grande arte, leva-nos a entender que sua obra é muito mais aprimorada que a dos brutalistas que o antecederam e que o influenciaram, principalmente no que diz respeito aos recursos narrativos empregados pelo autor de que tratamos aqui. Ainda assim, consideramos que o livro estudado é um romance policial, pois carrega todos os requisitos para tal: detetive (Mandrake), assassino (Camilo Fuentes), enigma (o significado da letra P e o conteúdo do VHS) e vítimas (as duas prostitutas marcadas com a letra P). Todos os elementos estão lá - ainda que o quebra-cabeça não tenha uma solução definitiva. Tal como a carta roubada do conto de Edgar Allan Poe apresenta-se apenas como uma desculpa para que Dupin exercite o seu poder analítico, o procurado VHS é um pretexto para que Mandrake manipule a arte de narrar a violência.

Nossa análise de $A$ grande arte permite, portanto, considerar que essa narrativa, mantendo as principais características de romance policial, sobressai relativamente às demais da mesma modalidade dada a maestria do escritor no que tange à estruturação do discurso. Se alguns críticos têm ressaltado o refinamento linguístico de tal obra, pudemos demonstrar que os aspectos próprios da história, das personagens do romance policial são transmitidos por meio de requintados recursos discursivos concernentes a outras categorias como a instância narrativa e a focalização. 
Referências bibliográficas

ARISTÓTELES. "Poética”. In: Aristóteles, Horácio, Longino. A poética clássica. Trad. Jaime Bruna. São Paulo: Cultrix, 2005.

BOILEAU, Pierre; NARCEJAC, Thomas. O romance policial. Trad. Valter Kehdi. São Paulo: Ática, 1991.

CANDIDO, Antonio. A educaçâo pela noite. Rio de Janeiro: Ouro sobre Azul, 2011.

FIGUEIREDO, Vera Lúcia Follain de. Os crimes do texto: Rubem Fonseca e a ficção contemporânea. Belo Horizonte: Editora UFMG, 2003.

FONSECA, Rubem. A grande arte. São Paulo: Companhia das Letras, 1990.

FOSTER, Hal. O retorno do real: a vanguarda no final do século XX. Trad. Célia Euvaldo. São Paulo: Ubu Editora, 2017.

GENETTE, Gérard. Discurso da narrativa. Trad. Fernando Cabral Martins. Lisboa: Vega, [197-].

MANDEL, Ernest. Delícias do crime. Trad. Nilton Goldmann. São Paulo: Busca Vida, 1988.

PELLEGRINI, Tânia. A imagem e a letra: aspectos da ficção brasileira contemporânea. Campinas: Mercado de Letras; São Paulo: Fapesp, 1999.

REIMÃO, Sandra Lúcia. O que é romance policial. São Paulo: Brasiliense, 1983.

RICOEUR, Paul. Tempo e narrativa. Trad. Márcia Valéria Martinez Aguiar. São Paulo: WMF Martins Fontes, 2010. 
Maria Célia de Moraes Leonel possui graduação em Letras pela Fundação Dom Aguirre (1968), mestrado em Letras-Literatura Brasileira pela Universidade de São Paulo (1976) e doutorado em Letras-Literatura Brasileira pela Universidade de Sáo Paulo (1985). É livre-docente (1998) (UNESP) e professora titular (2007) da Universidade Estadual Paulista Júlio de Mesquita Filho. Tem experiência na área de Letras, com ênfase em Literatura Brasileira e Teorias e crítica da narrativa, pesquisando, principalmente, os seguintes temas: narrativas brasileiras, modernismo brasileiro, prosadores brasileiros como Guimarães Rosa, Machado de Assis e Graciliano Ramos, teorias e crítica da narrativa, literatura e história. Docente e orientadora do Programa de Pós-graduação em Estudos Literários da FCL/UNESP-Araraquara.

E-mail: mcleonel@fclar.unesp.br

Murilo Eduardo dos Reis possui graduaçáo em Letras (2014) e mestrado em Estudos Literários (2018) pela Universidade Estadual Paulista. Seguindo a linha de Teorias e Crítica da Narrativa, desenvolveu trabalhos voltados para manifestaçóes literárias da violência em narrativas dos escritores Guimarães Rosa e Rubem Fonseca. Autor do livro de contos "Identidades secretas" (Lamparina Luminosa, 2016), atua como professor de Literatura e Língua Alemã.

E-mail: muriloreis86@gmail.com 